\title{
Glucosinolates are produced in trichomes of Arabidopsis thaliana
}

\author{
Henning Frerigmann ${ }^{1}$, Christoph Böttcher ${ }^{2}$, Dunja Baatout ${ }^{1}$ and Tamara Gigolashvili ${ }^{1}$ * \\ Universität zu Köln, Biozentrum Köln, Botanisches Institut, Köln, Germany \\ 2 Department of Stress and Developmental Biology, Leibniz Institute of Plant Biochemistry, Halle/Saale, Germany
}

\author{
Edited by: \\ Stanislav Kopriva, John Innes \\ Centre, UK \\ Reviewed by: \\ Masami Y. Hirai, RIKEN Plant \\ Science Center, Japan \\ Cornelia Herschbach, \\ Albert-Ludwigs-University Freiburg, \\ Germany \\ *Correspondence: \\ Tamara Gigolashvili, Universität zu \\ Köln, Biozentrum Köln, Botanisches \\ Institut, Zülpicher Street 47 B, 50674 \\ Köln, Germany. \\ e-mail: t.gigolashvili@uni-koeln.de
}

\begin{abstract}
Glucosinolates (GS) are important plant secondary metabolites in plant resistance to herbivores, bacteria, and fungi, which have been shown to be accumulating in different organs and tissue types at varying concentrations. There are more than 200 GS species found in order Brassicales and presence of these compounds is well documented on organ-specific but not on cell-specific level. We used UPLC/ESI-QTOF-MS to measure the presence of GS and qRT-PCR to analyse the expression of GS biosynthetic and regulatory genes in isolated Arabidopsis thaliana trichomes. Trichomes of Arabidopsis are shown to synthesize chemoprotective aliphatic glucosinolates (AGS) and indolic glucosinolates (IGS), which are known for their biological activities against fungi, bacterial pathogens, or herbivores. UPLC/ESI-QTOF-MS analysis of various IGS mutants reveal increased or decreased levels of IGS in trichomes of gain- and loss-of-function mutants correspondingly. Using pMYB51/HIG1-uidA and pMYB28/PMG1/HAG1-uidA reporter plants we demonstrate that production of these important compounds is activated in trichomes of leaves or inflorescences in response to wounding. Since trichomes represent the first interface in plant-environment interactions, the possible role of GS containing trichomes in plant defense or signaling is discussed.
\end{abstract}

Keywords: aliphatic glucosinolates (AGS), Arabidopsis, indolic glucosinolates (IGS), MYB-transcription factors, MYB51, MYB28, regulation of glucosinolate biosynthesis, trichomes

\section{INTRODUCTION}

Due to their sessile life style plants are exposed to numerous stresses, including varying light intensities, wind, extreme temperatures, shortage of water and nutrients, pathogen, and herbivore attack. The plant epidermis and epidermis-derived trichomes represent the first interface in plant-environment interactions. It is therefore not surprising that trichomes often contain defense metabolites (Levin, 1973). Multicellular glandular trichomes, which are found on the leaf surface of many plant species such as Solanum habrochaites (wild tomato), Nicotiana tabacum (tobacco), Ocimum basilicum (sweet basil), and Mentha piperita (peppermint) are able to synthesize and/or secrete various chemical compounds such as organic acids, polysaccharides, proteins, terpenes, phenolic compounds, glucose esters, and salts (Kelsey, 1984; Navasero and Ramaswamy, 1991; Walters et al., 1991; Gershenzon et al., 1992; McCaskill et al., 1992; Wang et al., 2001). By contrast, the leaf hairs of Arabidopsis thaliana are non-glandular single-cell hairs that develop from epidermal cells and are found on most aerial organs (Hülskamp and Schnittger, 1998). Generally, the non-glandular trichomes are believed to be physically defensive structures, and it has been demonstrated that induced plant response to herbivory correlates with an increased number of trichomes per leaf (Mauricio and Rausher, 1997; Agrawal, 2000; Clauss et al., 2006). It is

Abbreviations: GS, glucosinolates; IGS, indolic glucosinolates; AGS, aliphatic glucosinolats; ITCs, isothiocyanates. also reported that the production of trichomes is correlated with reduced damage from insect herbivores in natural populations of the perennial herb Arabidopsis lyrata (Kivimaki et al., 2007). Furthermore, the specialist herbivore Pieris rapae performed better on trichomeless gll mutant than on wild-type (Col-0) plants (Reymond et al., 2004). Finally, genome-wide gene expression analyses of trichomes (Affymetrix ATH-1 chip) revealed high transcript levels of some genes involved in anthocyanin, flavonoid, and glucosinolate (GS) pathways compared to leaves (Jakoby et al., 2008; Marks et al., 2008). Such biosynthesis of secondary and defense compounds suggest an important role of trichomes in plant defense and protection (Jakoby et al., 2008). Although there are many reports that link glandular and non-glandular trichomes with herbivore attacks (Ehleringer et al., 1976; Wagner, 1991; Simmons and Gurr, 2005), the ecological significance of non-grandular trichomes in chemical defence is still a matter of debate. It is even not clear if corresponding mRNAs (for example, involved in the biosynthesis of secondary compounds) or their end products (corresponding metabolites) are indeed present in the trichomes of the model Arabidopsis plant.

Here, we report for the first time that trichomes of Arabidopsis are able to synthesize a class of phytoprotective secondary compounds known as GS. There are more than 200 different GS known in order Brassicales (Clarke, 2010) and trichomes of Arabidopsis build up the aliphatic glucosinolates (AGS) and indolic glucosinolates (IGS). Trichomes of the loss-of- and 
gain-of-function mutants of IGS biosynthetic and regulatory genes accumulated different levels of IGS than wild-type trichomes. We demonstrate that not only mRNAs of genes required for the biosynthesis and degradation of GS, but also the mRNAs of MYB transcription factors controlling biosynthesis of these GS are present in trichomes. Expression of MYB transcription factors is rapidly induced upon tissue damage suggesting possible role of GS in plant defense in Arabidopsis. We believe that the ability to activate GS biosynthesis in trichomes could be an important feature of plants during plant biotic interactions.

\section{MATERIALS AND METHODS PLANT GROWTH}

A. thaliana (Columbia 0) plants were grown in a growth chamber under an $8 \mathrm{~h}$ light $\left(120 \mu \mathrm{mol} \mathrm{m} \mathrm{m}^{-2} \mathrm{~s}^{-1}\right) / 16 \mathrm{~h}$ dark regime at day/night temperatures of $21^{\circ} \mathrm{C} / 18^{\circ} \mathrm{C}$ and at $40 \%$ relative humidity.

\section{GAIN- AND LOSS-OF-FUNCTION Arabidopsis MUTANTS}

All Arabidopsis lines used here are in the Columbia (Col-0) background and were isolated as reported previously. The T-DNA insertion mutant in MYB51/HIG1 (High Indolic Glucosinolate 1) gene is a GABI-Kat line [GK228B12; (Gigolashvili et al., 2007a)] and the gain-of-function mutant HIG1-1D of the MYB51/HIG1 gene was isolated from a population of activation-tagged plants (Gigolashvili et al., 2007a). The cyp79b2cyp79b3 mutant was previously isolated by (Zhao et al., 2002) and seeds were kindly provided by the authors.

\section{PROMOTERS OF R2R3 MYB TRANSCRIPTION FACTORS AND HISTOCHEMICAL GUS STAINING}

The cloning procedure for the promoters of MYB51/HIG1 and MYB28/PMG1/HAG1 was performed as previously described (Gigolashvili et al., 2007a,b).

Induced expression of ProMYB51/HIG1-uidA and ProMY28/PMG1/HAG1-uidA constructs in trichomes after wounding was analyzed either on entire plants, which were still grown in pots, or on detached leaf and stem pieces. Leaves of ProMYB51/HIG1-uidA reporter transgenic lines and inflorescences of ProMYB28/PMG1/HAG1-uidA transgenic lines were wounded by scalpel or damaged by small scissors, which was immediately followed by $\beta$-glucuronidase staining in a $0.1 \%$ $\mathrm{X}$-Gluc solution as reported previously (Gigolashvili et al., 2007a). After overnight incubation at $37^{\circ} \mathrm{C}$ tissues were destained in $70 \%$ ethanol and analyzed microscopically.

\section{ISOLATION OF TRICHOMES}

The preparation method was modified from (Marks et al., 2008). In short, $1.5 \mathrm{~g}$ freshly harvested leaf material and $50 \mathrm{mg}$ glass beads $(60 / 80 \mu \mathrm{m})$ were mixed and vortexed with $15 \mathrm{ml} \mathrm{PBS/EGTA-buffer} \mathrm{(139} \mathrm{mM} \mathrm{KCl,} 10 \mathrm{mM} \mathrm{K}_{2} \mathrm{HPO}_{4}, 2 \mathrm{mM}$ $\mathrm{KH}_{2} \mathrm{PO}_{4}, \mathrm{pH} 7,4 ; 50 \mathrm{mM}$ EGTA $\left.\mathrm{pH} 7,5\right)$ in a 50-ml Falcon tube. The procedure ( $30 \mathrm{~s}$ vortexing and $30 \mathrm{~s}$ chilling at $4^{\circ} \mathrm{C}$ ) was repeated four times. The supernatant was poured into a new test tube and the leaf material was washed twice with PBS. The supernatants were combined and filtered over a $100 \mu \mathrm{m}$ sieve. The sieve was rinsed with PBS to collect the trichomes. The solution was centrifuged for $90 \mathrm{~s}$ at $150 \times g$.

To confirm the integrity of the isolated trichomes they were examined by light microscopy (Figures A1A-C) and frozen at $-80^{\circ} \mathrm{C}$, or freeze-dried for further analysis. To find out if applied isolation procedure resulted in the damage of cell membranes, isolated trichomes were stained by trypan blue followed by several washing steps and microscopical examination of single trichomes (Figures A1D-F).

\section{RNA EXTRACTION AND EXPRESSION ANALYSIS}

Total RNA was isolated from trichomes by the Trisure method (BIOLINE), according to the manufacturer's instructions. A maximum of $5 \mu \mathrm{g}$ RNA was reverse-transcribed using SuperScriptII Reverse Transcriptase (Life Technologies). Gene expression was analyzed by real-time quantitative analysis (qRT-PCR) using the fluorescent intercalating dye SYBRGreen in a GeneAmp_5700 Sequence Detection System (Applied Biosystems). To amplify gene targets a standard qRT-PCR protocol from Life Technologies was applied: $95^{\circ} \mathrm{C}$ for $10 \mathrm{~min}$ denaturation, 40 cycles of $95^{\circ} \mathrm{C}$ for $15 \mathrm{~s}$ and $60^{\circ} \mathrm{C}$ for $1 \mathrm{~min}$ annealing and elongation in one step. The Arabidopsis At2g28390 gene belonging to the SAND family was used as an internal standard (Czechowski et al., 2005). Relative quantification of expression levels was performed using the comparative $\mathrm{Ct}$ method, and the calculated relative expression values were normalized to the wild-type expression level (wild type $=1$ ) or to the expression levels of the same gene in leaves (leaves $=1$ ). Primer sequences for the qRT-PCR are listed in Table A1. Three biological and two technical replicates were used for the analysis.

\section{PREPARATION OF METHANOLIC TRICHOME AND LEAF EXTRACTS AND ANALYSIS BY UPLC/ESI-OTOF-MS}

Freeze-dried leaf/trichome material (7-12 mg) was accurately weighed into 2-mL tubes. After addition of steel balls $(\varnothing 2 \mathrm{~mm}$, Retsch) and cooling in liquid nitrogen, the samples were homogenized for $4 \mathrm{~min}$ at $30 \mathrm{~Hz}$ using a MM301 ball mill (Retsch) and kept frozen on dry ice until extraction. For that purpose, $200 \mu \mathrm{L} 80 \%$ aqueous methanol, precooled at $-40^{\circ} \mathrm{C}$, were added. Afterwards, the samples were immediately vortexed for $20 \mathrm{~s}$, sonicated for $10 \mathrm{~min}$ at $20^{\circ} \mathrm{C}$ and centrifuged for $10 \mathrm{~min}$ at $19,000 \times g$. The supernatants were transferred to new $2-\mathrm{ml}$ tubes and the remaining pellets subjected to a second extraction using $200 \mu \mathrm{L} 80 \%$ aqueous methanol. The combined extracts were evaporated to dryness in a vacuum centrifuge at $30^{\circ} \mathrm{C}$, reconstituted in $10 \mu \mathrm{L} 40 \%$ aqueous methanol permg dry weight, sonicated for $10 \mathrm{~min}$ at $20^{\circ} \mathrm{C}$ and centrifuged for $10 \mathrm{~min}$ at $19,000 \times g$. The supernatants $(2.8 \mu \mathrm{L}$, full loop injection) were separated on an Acquity UPLC system (Waters) equipped with a HSS T3 column $(100 \times 1.0 \mathrm{~mm}$, particle size $1.8 \mu \mathrm{m}$; Waters) using the following gradient program at a flow rate of $150 \mu \mathrm{L} / \mathrm{min}$ : $0-1 \mathrm{~min}$, isocratic 95\% A (water, $0.1 \%$ formic acid), $5 \% \mathrm{~B}$ (acetonitrile, $0.1 \%$ formic acid); $1-16 \mathrm{~min}$, linear from 5 to $95 \% \mathrm{~B} ; 16-18 \mathrm{~min}$, isocratic $95 \% \mathrm{~B} ; 18-20 \mathrm{~min}$, isocratic $5 \%$ B. Eluted compounds were detected from $\mathrm{m} / \mathrm{z} 100-1000$ using a MicroTOF-Q hybrid quadrupole time-of-flight mass 
spectrometer (Bruker Daltonics) equipped with an Apollo II electrospray ion source in positive and negative ion mode. For instrument settings and calibration see (Bottcher et al., 2009). Target compounds were relatively quantified by integrating the following extracted ion chromatograms $(\mathrm{m} / \mathrm{z}$-width \pm 0.02$)$ : 8-MeSO-octyl-GS $\left(\mathrm{C}_{16} \mathrm{H}_{31} \mathrm{NO}_{10} \mathrm{~S}_{3}\right), \quad t_{r}=192 \mathrm{~s}, \quad \mathrm{~m} / z \quad 492.10$ $[\mathrm{M}-\mathrm{H}]^{-} ; 7-\mathrm{MeSO}$-heptyl-GS $\left(\mathrm{C}_{15} \mathrm{H}_{29} \mathrm{NO}_{10} \mathrm{~S}_{3}\right), t_{r}=143 \mathrm{~s}, \mathrm{~m} / z$ $478.09\left[^{\mathrm{M}-\mathrm{H}}\right]^{-}$; 4-MeSO-butyl-GS $\left(\mathrm{C}_{12} \mathrm{H}_{23} \mathrm{NO}_{10} \mathrm{~S}_{3}\right), t_{r}=42 \mathrm{~s}$, $m / z 436.04[\mathrm{M}-\mathrm{H}]^{-}$; I3M-GS $\left(\mathrm{C}_{16} \mathrm{H}_{20} \mathrm{~N}_{2} \mathrm{O}_{9} \mathrm{~S}_{2}\right), t_{r}=168 \mathrm{~s}, \mathrm{~m} / z$ $447.05[\mathrm{M}-\mathrm{H}]^{-} ; 4-\mathrm{MeO}-\mathrm{I} 3 \mathrm{M}-\mathrm{GS}\left(\mathrm{C}_{17} \mathrm{H}_{22} \mathrm{~N}_{2} \mathrm{O}_{10} \mathrm{~S}_{2}\right), t_{r}=215 \mathrm{~s}$, $477.06[\mathrm{M}-\mathrm{H}]^{-} ; 1-\mathrm{MeO}-\mathrm{I} 3 \mathrm{M}-\mathrm{GS}\left(\mathrm{C}_{17} \mathrm{H}_{22} \mathrm{~N}_{2} \mathrm{O}_{10} \mathrm{~S}_{2}\right), t_{r}=252 \mathrm{~s}$, $477.06[\mathrm{M}-\mathrm{H}]^{-} ; 8-\mathrm{MeSO}$-octyl-NCS $\left(\mathrm{C}_{10} \mathrm{H}_{19} \mathrm{NOS}_{2}\right), t_{r}=492 \mathrm{~s}$, $m / z \quad 256.08 \quad[\mathrm{M}+\mathrm{Na}]^{+} ;$7-MeSO-heptyl-NCS $\left(\mathrm{C}_{9} \mathrm{H}_{17} \mathrm{NOS}_{2}\right)$, $t_{r}=441 \mathrm{~s}, \quad m / z \quad 242.06 \quad[\mathrm{M}+\mathrm{Na}]^{+} ; \quad$ 4-MeSO-butyl-NCS $\left(\mathrm{C}_{6} \mathrm{H}_{11} \mathrm{NOS}_{2}\right), t_{r}=270 \mathrm{~s}, \quad m / z \quad 200.02 \quad[\mathrm{M}+\mathrm{Na}]^{+} ; 8-\mathrm{MeSO}-$ octyl-CN $\left(\mathrm{C}_{10} \mathrm{H}_{19} \mathrm{NOS}\right), t_{r}=334 \mathrm{~s}, \quad m / z \quad 224.11 \quad[\mathrm{M}+\mathrm{Na}]^{+}$; 7-MeSO-heptyl-CN ( $\left.\mathrm{C}_{9} \mathrm{H}_{17} \mathrm{NOS}\right), \quad t_{r}=275 \mathrm{~s}, \quad \mathrm{~m} / z \quad 210.09$ $[\mathrm{M}+\mathrm{Na}]^{+} ; 4$-MeSO-butyl-NCS $\left(\mathrm{C}_{6} \mathrm{H}_{11} \mathrm{NOS}\right), t_{r}=68 \mathrm{~s}, \mathrm{~m} / z$ $168.05[\mathrm{M}+\mathrm{Na}]^{+} ; 8-\mathrm{MeSO}$-octyl- $\mathrm{NH}_{2}\left(\mathrm{C}_{9} \mathrm{H}_{21} \mathrm{NOS}\right), t_{r}=144 \mathrm{~s}$, $m / z \quad 192.14[\mathrm{M}+\mathrm{H}]^{+}$. Other known AGS in Arabidopsis were under detection limits in methanolic extracts of trichomes. GS detected in trichome extracts were referenced and quantified using HPLC of Arabidopsis leaf extracts as described previously (Gigolashvili et al., 2007b). Isothiocyanates (ITCs) were validated using commercially available standards (LKT Laboratories). Nitriles were putatively identified using accurate mass measurements and tandem-MS experiments. Accurate mass measurements and collision-induced mass spectra are listed in Tables A2 and A3. 8-MeSO-octyl$\mathrm{NH}_{2}$ was prepared from the corresponding ITC by acidic hydrolysis.

\section{RESULTS \\ GLUCOSINOLATE BIOSYNTHETIC GENES ARE EXPRESSED IN TRICHOMES}

qRT-PCR analysis for the expression of GS biosynthetic genes and regulators in wild type Arabidopsis trichomes was performed. Transcriptional profiling of representative genes involved in GS metabolism demonstrated the presence of transcripts belonging to the GS pathway. Figure 1A depicts expression levels of exemplarily chosen genes required for the biosynthesis of aliphatic (MAM1, CYP83A1), indolic (CYP79B3, CYP83B1) GS (corresponding biosynthetic pathways are shown in Figure A2), or breakdown of GS (TGG1) in isolated trichome extracts compared to expression levels in whole leaves. These results confirm the presence of biosynthetic and breakdown genes of the GSmyrosinase system in trichomes.

However, not only GS biosynthetic genes, but also genes encoding transcription factors, that are known to control the biosynthesis of GS (Gigolashvili et al., 2007a,b, 2008; Hirai et al., 2007; Sonderby et al., 2007, 2010; Malitsky et al., 2008) are transcribed in trichomes. As illustrated in Figures 1B,C, mRNA of both groups of transcription factors, namely MYB28 (PMG1/HAG1), MYB29 (PMG2/HAG2), and MYB76 (HAG3) as well as MYB51/HIG1, MYB122 (HIG2), and MYB34 (ATR1), which regulate biosynthesis of AGS and IGS (Figure A2), respectively, are present in Arabidopsis trichomes.

\section{INDOLIC AND ALIPHATIC GLUCOSINOLATES ARE PRESENT IN TRICHOME CELLS}

The presence of transcripts of structural and regulatory genes of GS biosynthesis in trichomes suggests that these chemoprotective secondary metabolites are synthesized in these cells. To further substantiate this finding, we screened for AGS and IGS in extracts of isolated trichomes of wild-type plants and IGS mutants, using UPLC/ESI-QTOF-MS as described previously (Bottcher et al., 2008). As shown in Figure 2A, the trichomes of wild-type plants and mutants accumulated some methylsulphinylalkyl (4-MeSObutyl-, 8-MeSO-octyl-GS) and indolic (I3M-, 4-MeO-I3M- and 1-MeO-I3M-GS) GS, whereas methylthioalkyl GS were below the detection limit. Furthermore, analyses of GS in trichomes of loss-of-function IGS mutants revealed lower IGS levels in trichomes of myb51/hig1-1 and cyp79b2cyp79b3 mutant plants than in wild type (Col-0). Observed GS levels in trichomes of Col-0, myb51/hig1-1 and MYB51-1D/HIG1-1D correlated well with the amount of MYB51/HIG1 mRNA (Figure 2B). The cyp79b2cyp79b3 mutant, which is defective in the production of IAOx-derived metabolites (Zhao et al., 2002), did not contain any detectable amounts of I3M-, 4-MeO-I3M- or 1-MeO-I3M-GS (Figure 2A). Conversely, the gain-of-function mutant MYB511D/HIG1-1D contained higher than wild-type levels of I3M- and 4-MeO-I3M-GS. Amounts of all measured GS in trichomes of wild type and mutant plants were present at about 100 times lower levels than in leaves (Figure A3). However, even these amount of GS have, most probably, an important biological activity in vivo, as, for example, comparable amounts of GS have been reported to have sufficient antimicrobial activity in vitro (Tierens et al., 2001).

\section{PROMOTERS OF R2R3 MYBS CONTROLLING BIOSYNTHESIS OF GLUCOSINOLATES ARE INDUCED UPON PHYSICAL DAMAGE IN TRICHOMES}

Based on the finding that GS are synthesized in trichomes (Figure 2A) along with the presence of known MYB regulators (Figures 1B,C), we re-analyzed the activity of promoterreporter constructs of the main indolic (MYB51/HIG1) and aliphatic (MYB28/PMG1/HAG1) GS regulators. Indeed, as previously reported (Gigolashvili et al., 2007a,b), we could confirm activity of MYB51/HIG1 and MYB28/PMG1/HAG1 promoters in leaf hairs of Arabidopsis rosette leaves and hairs of inflorescences correspondingly (Figures 3A,B).

To identify whether the biosynthesis of GS in trichomes is also regulated by wounding, leaves and trichomes of ProMYB51/HIG1-uidA reporter transgenic lines and inflorescences of ProMYB28/PMG1/HAG1-uidA transgenic lines were wounded by scalpel or damaged by small scissors, which was immediately followed by $\beta$-glucuronidase staining and microscopic analysis of trichomes. To avoid additional induction of reporter constructs by detachment of leaves in experiment presented on Figures 3C-E, wounding and GUS staining were performed on entire plants with roots. Figures 3C-E demonstrate the induction of $\beta$-glucuronidase activity in both broken trichomes (Figure 3E) and trichomes of wounded leaves (Figure 3D) compared to unwounded ones (Figure 3C) of ProMYB51/HIG1-uidA reporter transgenic lines. As for the 

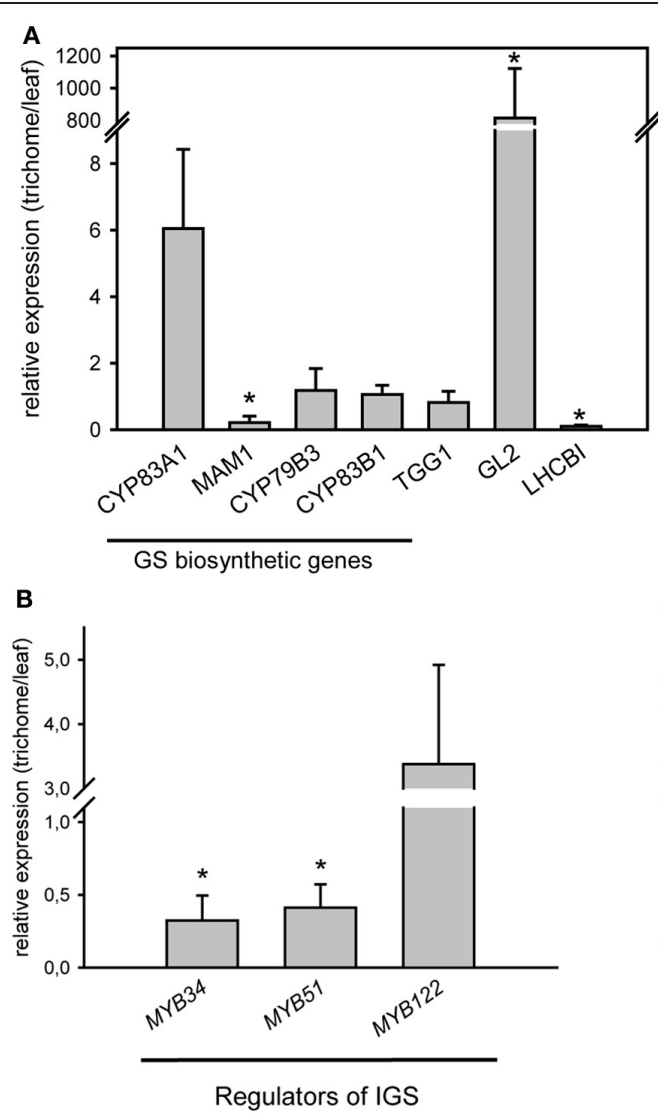

C

FIGURE 1 | Relative expression levels of GS biosynthetic and regulatory genes in trichomes of wild-type plants (Col-0). (A) Relative expression level of CYP79B3, MAM1, CYP83B1, CYP83A1, TGG1, GL2, and LHCBI in trichomes of wild-type plants; (B) Relative expression of indolic glucosinolate (IGS) regulators: MYB51/HIG1, MYB34 and MYB122; (C) Relative expression of aliphatic glucosinolate (AGS) regulators: MYB28, MYB29 and MYB76. Expression analysis of genes required for GS biosynthesis was performed on detached trichomes, which were collected as described in the Materials

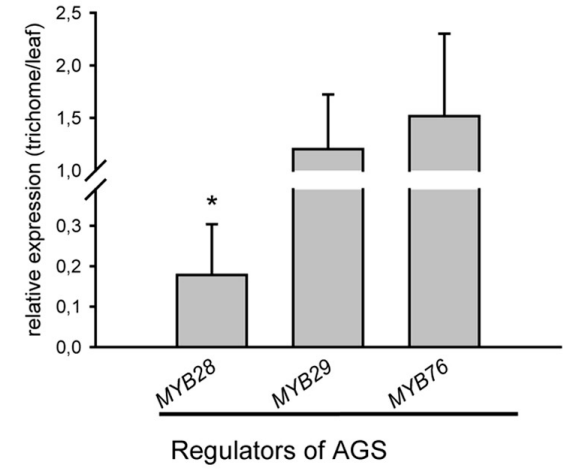

and Methods. GLABRA2 gene (GL2), which is mainly found in trichomes and $L H C B I$, which is expected to be found in photosynthetically active leaf tissue have been used as positive and negative controls for corresponding tissue types. Three biological and two technical replicates were used for the analysis. Error bars show SE of the mean. Relative gene expression levels are shown in trichomes vs. leaves (leaves $=1$ ). Significantly different values in trichomes vs. leaves are marked with asterisk (Student's $t$-test, $P<0.05)$.

reporter gene activity in ProMYB28/PMG1/HAG1-uidA transgenic lines, it was detectable in trichomes of wounded inflorescences (Figure 3G) against unwounded ones (Figure 3F), but not in leaves (not shown).

To assess whether the induction of GS biosynthesis correlates with the accumulation of ITCs, which are toxic for other organisms, methanolic extracts of detached trichomes were analyzed for various GS degradation products. The UPLC/ESI-QTOF-MS analyses of trichomes revealed comparable (for 4-MeSO-butylNCS) or even higher than in levels (for the 7-MeSO-heptyl-NCS and 8-MeSO-octyl-NCS) levels of ITCs derived from AGS. In addition, we could measure in the trichomes 8-MeSO-octylderived amine in amounts comparable with the leaves and traces of 8-MeSO-octyl-derived nitrile (Figure 4). Although we were able to detect nitriles derived from 4-MeSO-butyl- and 7-MeSOheptyl-GS in leaves, these compounds were below the detection limit in trichome extracts. Moreover, the degradation products of IGS (e.g., ascorbigens or indole-3-carbaldehydes) were also detectable only in leaf extracts (data not shown). GS degradation products measured in trichomes of Col- 0 could be generated during GS degradation or turnover in living cells (in vivo) or during isolation of trichomes, which is a mechanical stress per se, comparable to a mechanical stress caused by herbivores. Indeed, about $2-5 \%$ of trichomes showed a penetration of trypan blue dye into the cytosol (Figures A1D-F), which is an indication of, at least, plasma membrane damage. Taken together, these data indicate that trichomes are able to synthesize GS and to induce their production upon physical stress by inducing MYB transcription factors controlling biosynthesis of AGS and IGS.

\section{DISCUSSION}

The plant epidermis, covered with trichomes is an immediate interface in plant-environment interactions and an active role of trichomes in plant biotic and abiotic interactions has been suggested in numerous ecological studies. For instance, the negative correlation between trichome density and insect feeding and oviposition responses and/or the nutrition of larvae has been shown for Arabidopsis and other plant species (Mauricio and 


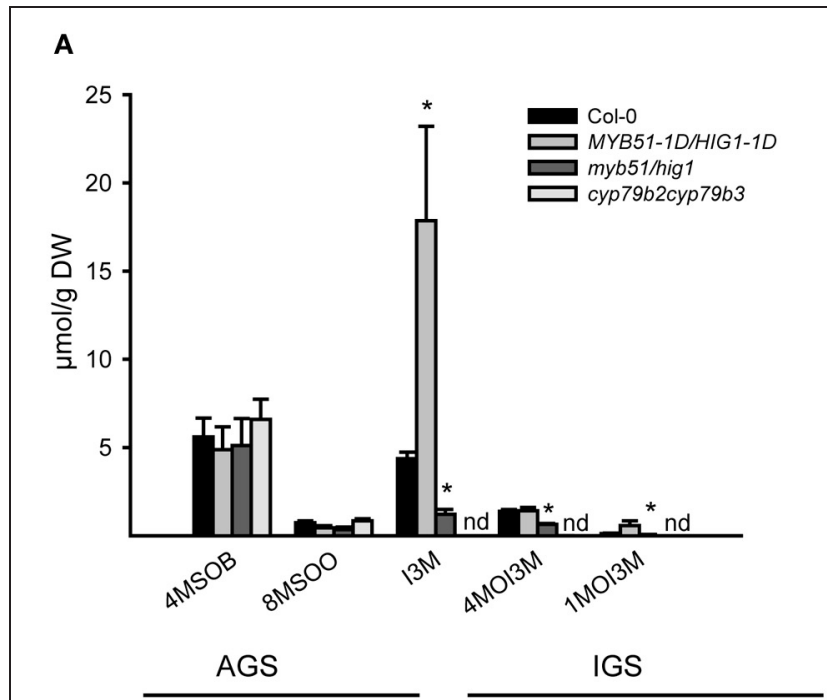

B

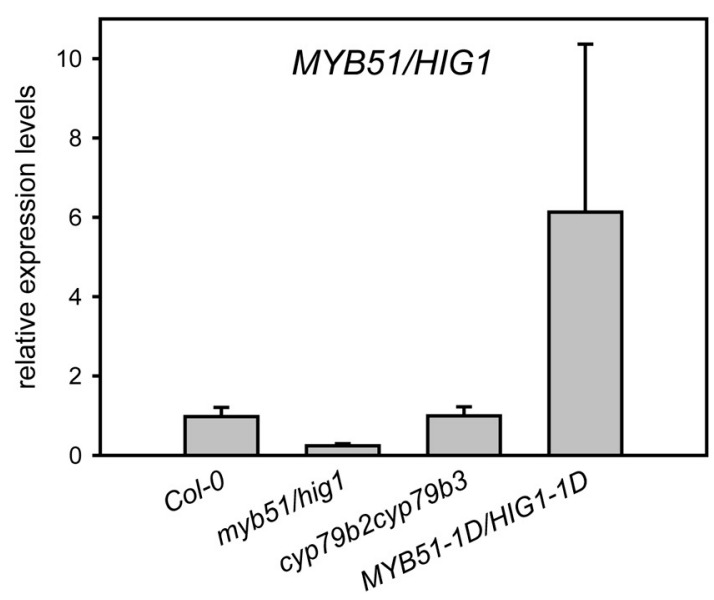

FIGURE 2 | Glucosinolate production in trichomes of $m y b 51 / h i g 1$, MYB51-1D/HIG1-1D and cyp79b2cyp79b3 mutants. (A) Aliphatic

glucosinolates (AGS) and indolic (IGS) glucosinolates have been quantified in methanolic extracts of detached trichomes of MYB51-1D/HIG1-1D, myb51/hig1, cyp79b2cyp79b3. 4-MeSO-butyl-GS (4MSOB),

8-MeSO-octyl-GS (8MSOO), I3M-GS, 4-MeO-I3M-GS (4MOI3M) and 1-MeO-I3M-GS (1MOI3M) are shown. (B) Relative steady-state level of MYB51/HIG1 mRNA in trichomes of GS mutants and wild-type (Col-0) plants. Comparative expression analysis of MYB51/HIG1 in myb51/hig1, MYB51-1D/HIG1-1D and cyp79b2cyp79b3 mutants vs. Col-0 $(=1)$ was performed on detached trichomes. Trichomes were collected as described in "Materials and Methods." Three biological and two technical replicates were used for the gRT-PCR analysis. Error bars show SE of the mean. ndnot detected. Significantly different values from the wild type at $P<0.05$ (Student's $t$-test) are marked by asterisk.

Rausher, 1997; Agrawal, 2000). The production of hooked trichomes and thorns has been reported for the herb plant Mentzelia pumila, which seems to be a direct plant defense mechanism against herbivore attack (Eisner et al., 1998). The toxic content of non-glandular trichomes of Glycine max (Levin, 1973) has been described to immobilize pathogens after cell disruption. Glandular trichomes can serve additionally in plant chemical
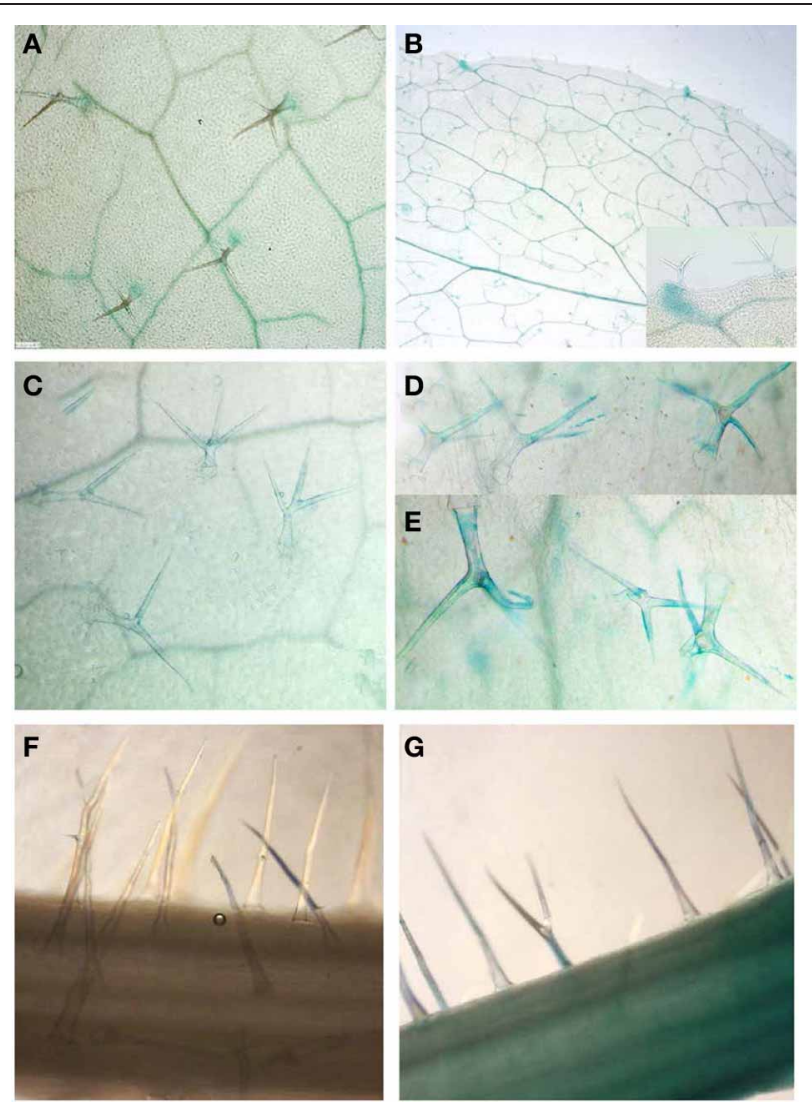

FIGURE 3 | Activity of MYB51/HIG1 and MYB28/PMG1/HAG1 promoters controlling the biosynthesis of IGS and AGS in Arabidopsis. (A,B) Basal activities of ProMYB51/HIG 1-uidA (A) and

ProMYB28/PMG 1/HAG1-uidA (B) in trichomes of detached Arabidopsis rosette leaves. (C,D) Expression of ProMYB51/HIG1-uidA construct in trichomes of entire plants with roots before (C) and after (D) wounding of rosette leaves. (E) Induced expression of the ProMYB51/HIG1-uidA construct in mechanically damaged trichomes of entire plants with roots. Damaged trichomes are still attached to the surface of leaves. $(\mathbf{F}, \mathbf{G})$ Induced expression of ProMY28/PMG1/HAG 1-uidA construct in trichomes before (F) and after (G) wounding of inflorescences. Leaves and inflorescences of ProMYB51/HIG1-uidA and ProMY28/PMG1/HAG1-uidA reporter transgenic lines were wounded by scalpel (or scissors) making five to six repeating $0,5 \mathrm{~cm}$ cuts along the corresponding tissue, and were immediately used for $\beta$-glucuronidase staining. Wounding response was restricted to the inflicted leaf and no systemic response in the trichomes of other leaves was observed.

defense, since their glands can exude terpenes, phenolics, alkaloids, or other substances, which are gustatory repellents of herbivores. Finally, microarray analysis revealed the presence of several secondary metabolites genes, including some GS biosynthetic genes, in isolated trichomes, indicating the possible protective function of trichomes (Jakoby et al., 2008; Marks et al., 2008).

\section{UNCOVERING GLUCOSINOLATES IN TRICHOMES OF Arabidosis}

In this paper we present data showing the presence of transcripts of GS biosynthesis and breakdown genes, as well as the presence of AGS and IGS in trichomes of Arabidopsis by 


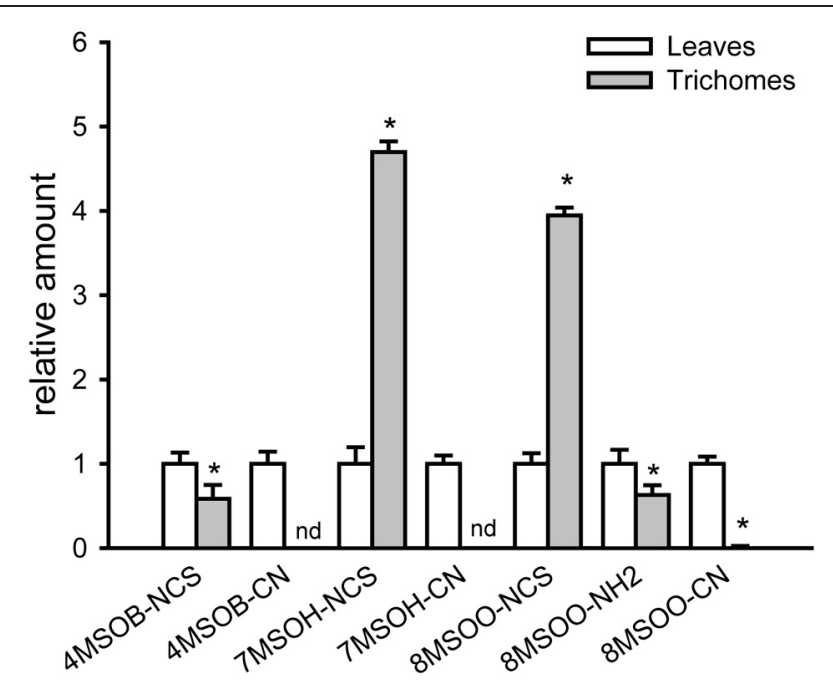

FIGURE 4 | GS degradation products are present in trichome extracts of wild-type (Col-0) plants. Relative amounts of GS degradation products in trichomes vs. leaves (peak area in leaves $=1$ ) are shown. Isothiocyanates (4-MeSO-butyl-NCS, 7-MeSO-heptyl-NCS, 8-MeSO-octyl-NCS), nitriles (4-MeSO- butyl-CN, 7-MeSO-heptyl-CN, 8-MeSO-octyl-CN) and 8-MeSO-octyl-derived amine (8-MeSO-octyl-NH2) have been measured in methanolic leaf and trichome extracts using UPLC/ESI-QTOF-MS. Data are normalized to corresponding dry weights of trichomes and leaves. nd- not detected. Significantly different values from the wild type at $P<0.05$ (Student's $t$-test) are marked by asterisk.

performing qRT-PCR and UPLC/ESI-QTOF-MS analyses of isolated trichomes. Herewith we could provide for the first time evidence for the presence of biologically active secondary compounds, like GS, in non-glandular trichomes of Arabidopsis, and, suggest in this way an active role of these compounds of plant hairs in plant-biotic interactions.

Using UPLC/ESI-QTOF-MS-based analysis of isolated trichomes, we show that several IGS and AGS, as well as several aliphatic ITCs, 8-MeSO-octyl-derived amine and minor amounts of 8-MeSO-octyl-derived nitrile are present in trichome extracts of Arabidopsis wild-type plants (Figures 2A and 4). Furthermore, using qRT-PCR analysis of isolated trichomes we demonstrated that along with the trichome-specific GLABRA2 (GL2) gene, the mRNAs of genes involved in the biosynthesis and regulation of IGS and AGS are also present in trichomes (Figure 1). An expression of leaf-specific gene $L H C B I$ was negligible in the cDNA prepared from trichomes, which excluded a possibility of contamination by leaves in our trichome extracts. Our data is in agreement with in silico data of (Jakoby et al., 2008) that demonstrated mRNAs of several GS biosynthetic genes, such as CYP83B1, UGT74B1, SOT16, or CYP83A1, UGT74B1, SOT18 in isolated trichomes.

To obtain insight into the constitutive production of GS in trichomes of Arabidopsis, we analyzed the accumulation of IGS in a set of IGS mutants. Trichomes of cyp79b2cyp79b3 and myb51/hig1 knock-out plants, which are known to be impaired in the production of IGS in leaves also showed decreased IGS levels in trichomes (Figure 2). The cyp79b2cyp79b3 mutant, which is known to completely lack IGS in leaves, was also not able to accumulate these compounds in trichomes. As expected, the levels of AGS, however, remained unaltered in these mutants. On the contrary, the MYB51-1D/HIG1-1D mutant, which is known to accumulate high levels of IGS in leaves (Gigolashvili et al., 2007a), also contained high IGS levels in trichomes. Altogether, these findings demonstrate that GS are synthesized in wild-type trichomes, and their biosynthesis in trichomes is controlled by the same set of biosynthetic and regulatory genes as in the leaves or seeds.

Although the presence of GS in trichomes is presented for the first time in this work, the spatial variations of some GS within the leaves (Shroff et al., 2008) as well as the knowledge about specific S-cells in plants, accumulating higher levels of GS (Koroleva et al., 2000, 2010) has been known since several years. GS accumulating S cells are known to contain about 19 times greater concentration of sulphur (and hence GS) than the surrounding tissues, providing the advantages of protecting the nutrient-rich phloem from herbivores (Shroff et al., 2008; Koroleva et al., 2010). In addition to the S-cells, it has been found that the cells of the outer margin of the leaf accumulate high amounts of sulphur (Koroleva et al., 2010), corresponding well to a specific localization of IGS (Shroff et al., 2008) and providing better defense from the herbivores, which usually bite leaf margins. Another study demonstrated accumulation of GS in the S-like specific root cell layers of canola. The highest GS concentrations were reported to be accumulating in two cell layers just below the outermost periderm layer, with up to 100 -fold higher concentrations than the mean value in the root (McCully et al., 2008). GS or GS-degradation products present is these specific root cells may be released into the rhizosphere to act as biologically active compounds during interaction with organisms living in soil.

\section{HOW MUCH GLUCOSINOLATES ARE PRODUCED OR NEEDED IN TRICHOMES?}

In comparison with leaves, levels of GS in trichomes are about 100 times lower, however, even these amounts could be enough to have, for example, an anti-microbial effect. Assuming all 4-MeSO-butyl-GS present in trichomes is converted into 4MeSO-butyl-NCS, the absolute amounts of 4-MeSO-butyl-NCS generated in trichomes will be comparable with the amounts of 4-MeSO-butyl-NCS reported by Tierens et al., 2001 to have sufficient antibacterial activities in vitro. However, the relative amounts of ITCs measured in trichomes were not 100 times lower than in leaves, but for some metabolites (like 4-MeSObutyl-NCS) were well comparable or for other (like 7-MeSOheptyl-NCS and 8-MeSO-octyl-NCS) even higher than in leaves. Thus, although trichomes accumulate much lower level of native GS than the leaves, GS breakdown products like ITCs are accumulating at comparable or even higher levels than in leaves, indicating better performance of ITC generation machinery of non-glandurar trichomes of Arabidopsis plants. Altogether our study is in agreement with previous works showing only weak correlation between mRNA level and its products like protein levels, enzyme activities or metabolite levels (Gygi et al., 1999; Piques et al., 2009; Sonderby et al., 2010). For some genes, steadystate levels of certain proteins were recorded with respective mRNA transcript levels that varied by as much as 30 -fold, at the 
same time, while the mRNA levels were of the same value, the protein levels varied by more than 20-fold (Gygi et al., 1999). Similar observations demonstrating an uncoupling of GS levels from the level of transcript of GS biosynthetic genes were made during analysis of the regulation of GS biosynthetic pathway (Sonderby et al., 2010). These authors suggested that "this uncoupling of chemotypes from biosynthetic transcripts suggests revising our view of the regulation of GS metabolism from a simple linear transcription factor-promoter model to a more modular system in which transcription factors cause similar chemotypes via non-overlapping regulatory patterns" (Sonderby et al., 2010).

\section{PRODUCTION OF GLUCOSINOLATE REGULATORS IN TRICHOMES IS INCREASED UPON WOUNDING}

As it was shown previously, the expression of the six R2R3-MYB transcription factors in leaves is positively regulated by different environmental stimuli, such as wounding or hormone treatment (Gigolashvili et al., 2007a, 2008; Hirai et al., 2007). To analyze if the production of GS regulators is also activated in trichomes, plants containing a promoter-uidA construct of the main indolic (MYB51/HIG1) and main aliphatic (MYB28/PMG1/HAG1) GS regulators were subjected to mechanical stress followed by $\beta$ glucuronidase activity assay. It could indeed be demonstrated that the expression of the main regulator of IGS and AGS in trichomes is induced upon wounding (Figures 3D-G) and this induction was mainly detectable in the trichomes of rosette leaves in the case of ProMYB51/HIG1-uidA plants and in the trichomes of inflorescences in ProMYB28/PMG1/HAG1-uidA reporter plants. This finding fits well with previous observation demonstrating that leaves and inflorescences are the main sites of IGS and AGS accumulation correspondingly (Brown et al., 2003; Sarsby et al., 2012). Altogether we could show that trichomes of Arabidopsis are not only able to synthesize different GS in trichomes of leaves and inflorescences, but are also capable of activating their production upon mechanical stress. However, it remains to be elucidated how different types of GS at different concentrations and in different cell types are used during interactions with various organisms.

\section{TRICHOME-LOCALIZED GLUCOSINOLATES AND THEIR POTENTIAL IN PLANT-PATHOGEN INTERACTIONS}

Following our discovery of GS biosynthesis pathway in trichomes, the relation of GS biosynthesis in trichomes with the production of biologically active GS catabolism products, which could affect the plant interaction with other organisms were analyzed. Upon disruption of tonoplast membrane of leaf mesophyll cells, vacuolar-localized GS (Agee et al., 2010; Klie et al., 2011; Krueger et al., 2011) are known to be released into the cytosol causing an activation of GS-mirosinase system and production of ESP- and NSP-dependent and independent GS degradation products (Burow et al., 2006, 2009; Wittstock and Burow, 2007; De Vos et al., 2008; Mumm et al., 2008; Burow and Wittstock, 2009). Trichomes of Arabidopsis (Col-0) wild-type plants were shown to accumulate diverse aliphatic ITCs, like 4-MeSO-butyl-NCS, 7-MeSO-heptyl-NCS, and 8-MeSO-octylNCS, low amounts of 8-MeSO-octyl-derived nitrile (8-MeSOoctyl-CN) and comparable with the level of 4-MeSOB- derived
ITC amine (8-MeSO-octyl-NH2), underlying the potential of GS-myrosinase system in this cell type (Figure 4). Higher level of ITC and low levels of nitriles are also in accordance with the presence of myrosinase (TGG1) transcripts in trichomes (Figure 1A), and with lower abundance of NSP transcripts in comparison with TGG1 (Marks et al., 2008). Ability to generate ITCs in trichomes could be considered as an advantageous feature of plants as positive role of GS in direct defense is usually attributed to the ITCs, which are toxic upon ingestion and/or contact (Wittstock et al., 2003). A recent study of (Fan et al., 2012), opened new insights about the role of ITCs in plant microbe-interactions and demonstrated that aliphatic ITCs are crucial for robust defenses that underpin non-host resistance in the Arabidopsis-Pseudomonas pathosystem. It can be, therefore, suggested that ITCs, which can be induced in trichomes, in analogy to ITCs induced in other parts of plants could be required in plant-bacterial interactions and/or plant defense against bacterial pathogens.

Interestingly, among GS catabolism products we detect significant amounts of amine derived from 8-MeSO-octyl-GS. GSderived amines are known to be generated in living cells in myrosinase-independent (or alternative GS catabolism) pathway as side products of GS degradation. Examples of such pathways are PEN2 and PYK10-mediated metabolism of GSs (Bednarek et al., 2009; Wittstock and Burow, 2010). However, biochemical structures of active molecules generated in PEN2- and PYK10mediated GS degradation are not known, most probably because they are highly active and are quickly detoxified in the cell. It is only known that IGS, like $4 \mathrm{MOI} 3 \mathrm{M}$ and $1 \mathrm{MOI} 3 \mathrm{M}$, but also partially I3M are used as substrates by both PEN2 and PYK10 (Bednarek et al., 2009; Wittstock and Burow, 2010). The facts that some amines could be detected in trichomes of Arabidopsis indicate that alternative GS degradation pathway could exist in living trichomes as well. This suggestion is supported by the observation in which we could measure comparably higher levels of IGS in trichomes but were not able to detect the typical degradation products of IGS such as ascorbigen or carbonyles. Thus, it may be that the fate of IGS in trichomes is additionally determined by PEN2 and PYK10-like enzymes. The absence of IGS degradation products in trichome extracts, along with the hardly detectable expression level of $L H C B I$ gene, provides additionally an independent proof of purity of trichome extracts. If contaminated by leaves, the metabolite profile of trichomes would phenocopy the profile of leaves, which is obviously not the case.

In principle and depending on the type of pathogen coming into contact with trichomes, all possible GS degradation products could be generated and employed during plant-pathogen interactions. Some of these compounds like ITCs accumulate at higher concentration in trichomes, and therefore could be used in direct defense. Others, like nitriles are present at lower concentrations, and therefore can play a role as signaling molecules. For example, a volatile GS degradation products released from the damaged tissue have been shown to have important function in tri-trophic interactions even at lower concentrations (Wittstock et al., 2003; Burow et al., 2006, 2009; De Vos et al., 2008; Mumm et al., 2008; Burow and Wittstock, 2009). 


\section{PERSPECTIVES FOR GLUCOSINOLATE RESEARCH IN TRICHOMES}

Our data demonstrate that trichomes are not only synthesizing GS at basal levels or regulate their production upon physical stress by inducing MYB transcription factors, but that they are also able to activate the GS breakdown pathway and to accumulate biologically active GS degradation products, like ITC at the levels comparable with leaves. The ability to rapidly release GS degradation compounds from damaged trichomes immediately after contact of plant trichomes with interacting organism, will, most probably, change an interaction scenario and serve for the improvement of plant fitness in complex environments.

Along with GS one may expect the presence of other defensive components in plant trichomes, which could be important in plant-environment interactions. For example, Wienkoop et al. (2004) have reported an accumulation of disease-related proteins like RPP5 like protein, or TIR-NBS-LRR in proteomics study of trichomes of Arabidopsis. Alternatively and using the metabolomics approach of primary metabolites in trichomes of Arabidopsis, Ebert et al. (2010) reported the presence of various precursors of secondary compounds in plants, like amino acids, fatty acids, lipids, sugars, polyols and indole-3-acetonitrile. Increased accumulation of defensive compounds like protease

\section{REFERENCES}

Agee, A. E., Surpin, M., Sohn, E.

J., Girke, T., Rosado, A., Kram,

B. W., et al. (2010). MODIFIED

VACUOLE PHENOTYPE1 is an arabidopsis myrosinase-associated protein involved in endomembrane protein trafficking. Plant Physiol. $152,120-132$.

Agrawal, A. A. (2000). Benefits and costs of induced plant defense for Lepidium virginicum (Brassicaceae). Ecology 81, 1804-1813.

Bednarek, P., Pislewska-Bednarek, M., Svatos, A., Schneider, B., Doubsky, J., Mansurova, M., et al. (2009). A glucosinolate metabolism pathway in living plant cells mediates broad-spectrum antifungal defense. Science 323, 101-106.

Bi, J. L., Murphy, J. B., and Felton, G. W. (1997). Antinutritive and oxidative components as mechanisms of induced resistance in cotton to Helicoverpa zea. J. Chem. Ecol. 23, 97-117.

Bottcher, C., Von Roepenack-Lahaye, E., Schmidt, J., Schmotz, C., Neumann, S., Scheel, D., et al. (2008). Metabolome analysis of Biosynthetic mutants reveals a diversity of metabolic changes and allows identification of a large number of new compounds in arabidopsis. Plant Physiol. 147, 2107-2120.

Bottcher, C., Westphal, L., Schmotz, C., Prade, E., Scheel, D., and Glawischnig, E. (2009). The multifunctional enzyme CYP71B15
(PHYTOALEXIN DEFICIENT3) converts cysteine-indole-3acetonitrile to camalexin in the indole-3-acetonitrile metabolic network of arabidopsis thaliana. Plant Cell 21, 1830-1845.

Brown, P. D., Tokuhisa, J. G., Reichelt, M., and Gershenzon, J. (2003). Variation of glucosinolate accumulation among different organs and developmental stages of Arabidopsis thaliana. Phytochemistry 62, 471-481.

Burow, M., Losansky, A., Muller, R., Plock, A., Kliebenstein, D. J., and Wittstock, U. (2009). The genetic basis of constitutive and herbivore-induced ESPindependent nitrile formation in arabidopsis. Plant Physiol. 149, 561-574.

Burow, M., Markert, J., Gershenzon, J., and Wittstock, U. (2006). Comparative biochemical charproteins from plants and insects that alter myrosinase-catalysed hydrolysis of glucosinolates. FEBS J. 273, 2432-2446.

Burow, M., and Wittstock, U. (2009). Regulation and function of specifier proteins in plants. Phytochem. Rev. 8, 87-99.

Clarke, D. B. (2010). Glucosinolates, structures and analysis in food. Anal. Methods 2, 310-325.

Clauss, M. J., Dietel, S., Schubert, G., and Mitchell-Olds, T. (2006). Glucosinolate and trichome defenses in a natural Arabidopsis acterization of nitrile-forming

inhibitors, the emission of volatiles attracting predators and parasites of herbivores (Takabayashi and Dicke, 1996; Geervliet et al., 1997; De Moraes et al., 1998; De Leo et al., 2001) or the reduction in plant nutritional quality for herbivores (Bi et al., 1997) have been reported to affect plant performance and their interaction with enemies. Therefore, the production of any defensive or signaling compounds in plants will be expected to result in changed plant environmental interaction, reduced performance of "plant enemies," better performance of "plant associates," thereby promoting plant survival in a continuously changing environment.

It can be assumed that in natural environments, where plants are constantly interacting with other organisms or are under the attack by a wide range of plant enemies, trichome-mediated chemical interactions may have a pronounced ecological importance for plants.

\section{ACKNOWLEDGMENTS}

This work was supported by the Deutsche Forschungsgemeinschaft. We would like to thank Dr. Kristen Panfilio for the critical reading of the manuscript. Tamara Gigolashvili wants to thank Prof. Dr. U.-I. Flügge for his continued support.

lyrata population. J. Chem. Ecol. 32, 2351-2373.

Czechowski, T., Stitt, M., Altmann, T., Udvardi, M. K., and Scheible, W. R. (2005). Genome-wide identification and testing of superior reference genes for transcript normalization in Arabidopsis. Plant Physiol. 139, 5.

De Leo, F., Bonade-Bottino, M., Ceci,

L. R., Gallerani, R., and Jouanin, L. (2001). Effects of a mustard trypsin inhibitor expressed in different plants on three lepidopteran pests. Insect Biochem. Mol. Biol. 31, 593-602.

De Moraes, C. M., Lewis, W. J., Pare, P. W., Alborn, H. T., and Tumlinson, J. H. (1998). Herbivore-infested plants selectively attract parasitoids. Nature 393, 570-573.

De Vos, M., Kriksunov, K. L., and Jander, G. (2008). Indole-3acetonitrile production from indole glucosinolates deters oviposition by Pieris rapae. Plant Physiol. 146, 916-926.

Ebert, B., Zoeller, D., Erban, A., Fehrle, I., Hartmann, J., Niehl, A., et al., (2010). Metabolic profiling of Arabidopsis thaliana epidermal cells. J. Exp. Bot. 61, 1321-1335.

Ehleringer, J., Bjorkman, O., and Mooney, H. A. (1976). Leaf pubescence - effects on absorptance and photosynthesis in a desert shrub. Science 192, 376-377.

Eisner, T., Eisner, M., and Hoebeke, E. R. (1998). When defense backfires: detrimental effect of a plant's protective trichomes on an insect beneficial to the plant. Proc. Natl. Acad. Sci. U.S.A. 95, 4410-4414.

Fan, J., Crooks, C., Creissen, G., Hill, L., Fairhurst, S., Doerner, P., et al. (2012). Pseudomonas sax genes overcome aliphatic isothiocyanate-mediated non-host resistance in arabidopsis. Science 331, 1185-1188.

Geervliet, J. B. F., Posthumus, M. A., Vet, L. E. M., and Dicke, M. (1997). Comparative analysis of headspace volatiles from different caterpillarinfested or uninfested food plants of Pieris species. J. Chem. Ecol. 23, 2935-2954.

Gershenzon, J., McCaskill, D. Rajaonarivony, J. I. M., Mihaliak, C., Karp, F., and Croteau, R. (1992). Isolation of secretory-cells from plant glandular trichomes and their use in biosynthetic-studies of monoterpenes and other gland products. Anal. Biochem. 200 130-138.

Gigolashvili, T., Berger, B., Mock, H. P., Müller, C., Weisshaar, B., and Flügge, U. I. (2007a). The transcription factor HIG1/MYB51 regulates indolic glucosinolate biosynthesis in Arabidopsis thaliana. Plant J. 50, 886-901.

Gigolashvili, T., Yatusevich, R., Berger, B., Müller, C., and Flügge, U. I. (2007b). The R2R3-MYB transcription factor HAG1/MYB28 is a regulator of methioninederived glucosinolate biosynthesis in Arabidopsis thaliana. Plant J. 51, 247. 
Gigolashvili, T., Engqvist, M., Yatusevich, M., Müller, C., and Flügge, U. I. (2008). HAG2/MYB76 and HAG3/MYB29 exert a specific and coordinated control on the regulation of aliphatic glucosinolate biosynthesis in Arabidopsis thaliana. New Phytol. 177, 627-642.

Gygi, S. P., Rochon, Y., Franza, B. R., and Aebersold, R. (1999). Correlation between protein and mRNA abundance in yeast. Mol. Cell. Biol. 19, 1720-1730.

Hirai, M. Y., Sugiyama, K., Sawada, Y., Tohge, T., Obayashi, T., Suzuki, A., et al. (2007). Omics-based identification of Arabidopsis Myb transcription factors regulating aliphatic glucosinolate biosynthesis. Proc. Natl. Acad. Sci. U.S.A. 104, 6478-6483.

Hülskamp, M., and Schnittger, A. (1998). Spatial Regulation of Trichome Formation in Arabidopsis Thalian. London: Academic Press.

Jakoby, M. J., Falkenhan, D., Mader, M. T., Brininstool, G., Wischnitzki, E., Platz, N., et al. (2008). transcriptional profiling of mature Arabidopsis trichomes reveals that NOECK encodes the MIXTAlike transcriptional regulator MYB106. Plant Physiol. 148, 1583-1602.

Kelsey, R. G. (1984). Glandular trichomes - a helpful taxonomic character for Artemisia-nova (Black Sagebrush). J. Range Manage. 37, 370-372.

Kivimaki, M., Karkkainen, K., Gaudeul, M., Loe, G., and Agren, J. (2007). Gene, phenotype and function: GLABROUS1 and resistance to herbivory in natural populations of Arabidopsis lyrata. Mol. Ecol. 16, 453-462.

Klie, S., Krueger, S., Krall, L., Giavalisco, P., Flugge, U.-I., Willmitzer, L., et al. (2011). Analysis of the compartmentalized metabolome - a validation of the non-aqueous fractionation technique. Front. Plant Sci. 2:55. doi: 10.3389/fpls.2011.00055

Koroleva, O. A., Davies, A., Deeken, R., Thorpe, M. R., Tomos, A. D., and Hedrich, R. (2000). Identification of a new glucosinolate-rich cell type in Arabidopsis flower stalk. Plant Physiol. 124, 599-608.

Koroleva, O. A., Gibson, T. M., Cramer, R., and Stain, C. (2010). Glucosinolate-accumulating S-cells in Arabidopsis leaves and flower stalks undergo programmed cell death at early stages of differentiation. Plant J. 64, 456-469.
Krueger, S., Giavalisco, P., Krall, L., Steinhauser, M.-C., Bussis, D. Usadel, B., et al. (2011). A topological map of the compartmentalized Arabidopsis thaliana leaf metabolome. PLoS ONE 6:e17806. doi: 10.1371/journal.pone. 0017806

Levin, D. A. (1973). The role of trichomes in plant defense. Q. Rev. Biol. 48, 3 .

Malitsky, S., Blum, E., Less, H., Venger, I., Elbaz, M., Morin, S., et al. (2008). The transcript and metabolite networks affected by the two clades of Arabidopsis glucosinolate biosynthesis regulators. Plant Physiol. 148, 2021-2049.

Marks, M. D., Betancur, L., Gilding, E., Chen, F., Bauer, S., Wenger, J. P., et al. (2008). A new method for isolating large quantities of Arabidopsis trichomes for transcriptome, cell wall and other types of analyses. Plant J. 56, 483.

Mauricio, R., and Rausher, M. D. (1997). Experimental manipulation of putative selective agents provides evidence for the role of natural enemies in the evolution of plant defense. Evolution 51, 1435-1444.

McCaskill, D., Gershenzon, J., and Croteau, R. (1992). Morphology and monoterpene biosynthetic capabilities of secretory-cell clusters isolated from glandular trichomes of peppermint (mentha-piperita L). Planta 187, 445-454.

McCully, M. E., Miller, C., Sprague, S. J., Huang, C. X., and Kirkegaard, J. A. (2008). Distribution of glucosinolates and sulphur-rich cells in roots of field-grown canola (Brassica napus). New Phytol. 180, 193-205.

Mumm, R., Burow, M., Bukovinszkine'kiss, G., Kazantzidou, E., Wittstock, U., Dicke, M., et al. (2008). Formation of simple nitriles upon glucosinolate hydrolysis affects direct and indirect defense against the specialist herbivore, pieris rapae. J. Chem. Ecol. 34, 1311-1321.

Navasero, R. C., and Ramaswamy, S. B. (1991). Morphology of leaf surface trichomes and its influence on egglaying by Heliothis-virescens. Crop Sci. 31, 342-353.

Piques, M., Schulze, W. X., Hoehne, M., Usadel, B., Gibon, Y., Rohwer, J., et al. (2009). Ribosome and transcript copy numbers, polysome occupancy and enzyme dynamics in Arabidopsis. Mol. Syst. Biol. 5, E1-E17.

Reymond, P., Bodenhausen, N., Van Poecke, R. M. P., Krishnamurthy, V., Dicke, M., and Farmer, E. E.
(2004). A conserved transcript pattern in response to a specialist and a generalist herbivore. Plant Cell 16, 3132-3147.

Sarsby, J., Towers, M. W., Stain, C., Cramer, R., and Koroleva, O. A. (2012). Mass spectrometry imaging of glucosinolates in Arabidopsis flowers and siliques. Phytochemistry $77,110-118$.

Shroff, R., Vergara, F., Muck, A., Svatos, A., and Gershenzon, J. (2008) Nonuniform distribution of glucosinolates in Arabidopsis thaliana leaves has important consequences for plant defense. Proc. Natl. Acad. Sci. U.S.A. 105, 6196-6201.

Simmons, A. T., and Gurr, G. M. (2005). Trichomes of Lycopersicon species and their hybrids: effects on pests and natural enemies. Agric. For. Entomol. 7, 265-276.

Sonderby, I. E., Burow, M., Rowe, H. C., Kliebenstein, D. J., and Halkier, B. A. (2010). A complex interplay of three R2R3 MYB transcription factors determines the profile of aliphatic glucosinolates in arabidopsis1[C][W][OA]. Plant Physiol. 153, 348-363.

Sonderby, I. E., Hansen, B. G., Bjarnholt, N., Ticconi, C., Halkier B. A., and Kliebenstein, D. J. (2007). A systems biology approach identifies a R2R3 MYB gene subfamily with distinct and overlapping functions in regulation of aliphatic glucosinolates. PLOS ONE 2:e1322. doi: 10.1371/journal.pone. 0001322

Takabayashi, J., and Dicke, M. (1996). Plant-carnivore mutualism through herbivore-induced carnivore attractants. Trends Plant Sci. 1, 109-113.

Tierens, K., Thomma, B. P. H., Brouwer, M., Schmidt, J., Kistner, K., Porzel, A., et al. (2001). Study of the role of antimicrobial glucosinolate-derived isothiocyanates in resistance of arabidopsis to microbial pathogens. Plant Physiol. 125, 1688-1699.

Wagner, G. J. (1991). Secreting glandular trichomes - more than just hairs. Plant Physiol. 96, 675-679.

Walters, D. S., Harman, J., Craig, R., and Mumma, R. O. (1991). Effect of temperature on glandular trichome exudate composition and pest resistance in geraniums. Entomol. Exp. Appl. 60, 61-69.

Wang, E. M., Wang, R., Deparasis, J., Loughrin, J. H., Gan, S. S., and Wagner, G. J. (2001). Suppression of a P450 hydroxylase gene in plant trichome glands enhances natural-product-based aphid resistance. Nat. Biotechnol. 19, 371-374.

Wienkoop, S., Zoeller, D., Ebert, B. Simon-Rosin, U., Fisahn, J., Glinski, M., et al. (2004). Cell-specific protein profiling in Arabidopsis thaliana trichomes: identification of trichome-located proteins involved in sulfur metabolism and detoxification. Phytochemistry 65, 1641-1649.

Wittstock, U., and Burow, M. (2007). Tipping the scales - specifier proteins in glucosinolate hydrolysis. IUBMB Life 59, 744-751.

Wittstock, U., and Burow, M. (2010). Glucosinolate breakdown in Arabidopsis: mechanism, regulation and biological significance. Arabidopsis Book 8, e0134.

Wittstock, U., Kliebenstein, D. J., Lambrix, V., Reichelt, M. and Gershenzon, J. (2003). "Glucosinolate hydrolysis and its impact on generalist and specialist insect herbivores," in Integrative Phytochemistry: From Ethnobotany to Molecular Ecology. Vol. 37, eds J. T. Romeo and R. A. Dixon (Amsterdam: Pergamon), 101-125.

Zhao, Y., Hull, A. K., Gupta, N. R., Goss, K. A., Alonso, J., Ecker, J. R., et al. (2002). Trp-dependent auxin biosynthesis in Arabidopsis: involvement of cytochrome P450s CYP79B2 and CYP79B3. Genes Dev. 16,3100 .

Conflict of Interest Statement: The authors declare that the research was conducted in the absence of any commercial or financial relationships that could be construed as a potential conflict of interest.

Received: 18 July 2012; accepted: 10 October 2012; published online: 30 October 2012.

Citation: Frerigmann H, Böttcher C, Baatout D and Gigolashvili T (2012) Glucosinolates are produced in trichomes of Arabidopsis thaliana. Front. Plant Sci. 3:242. doi: 10.3389/fpls.2012.00242

This article was submitted to Frontiers in Plant Metabolism and Chemodiversity, a specialty of Frontiers in Plant Science. Copyright () 2012 Frerigmann, Böttcher, Baatout and Gigolashvili. This is an open-access article distributed under the terms of the Creative Commons Attribution License, which permits use, distribution and reproduction in other forums, provided the original authors and source are credited and subject to any copyright notices concerning any third-party graphics etc. 


\section{APPENDIX}
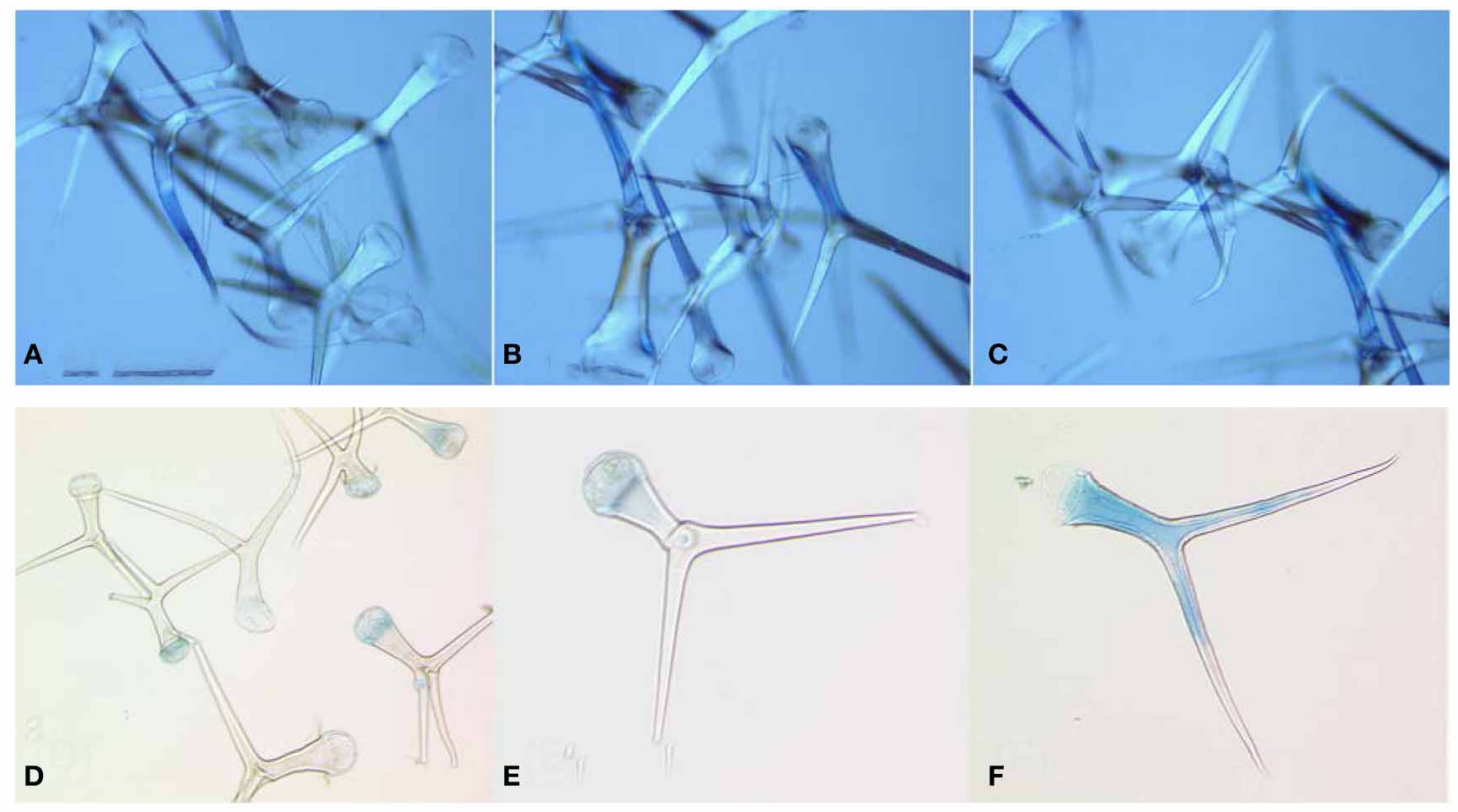

FIGURE A1 | Microscopic image of isolated trichomes.

(A-C) show three different biological replicates of independent trichome isolations. (D-F) Analysis of trichom intactness after trypan blue staining; (D) Pool of isolated trichomes after trypan blue staining; (E) Intact trichome. Trypan blue is only visible on the base of trichome where it was attached to the epidermal cells; (F) shows damaged trichome. Cytoplasm of cell is stained in blue because of destruction of inner membranes and dye penetration into the cell. About $2-5 \%$ of trichomes showed visible staining of the cell cytoplasm. 


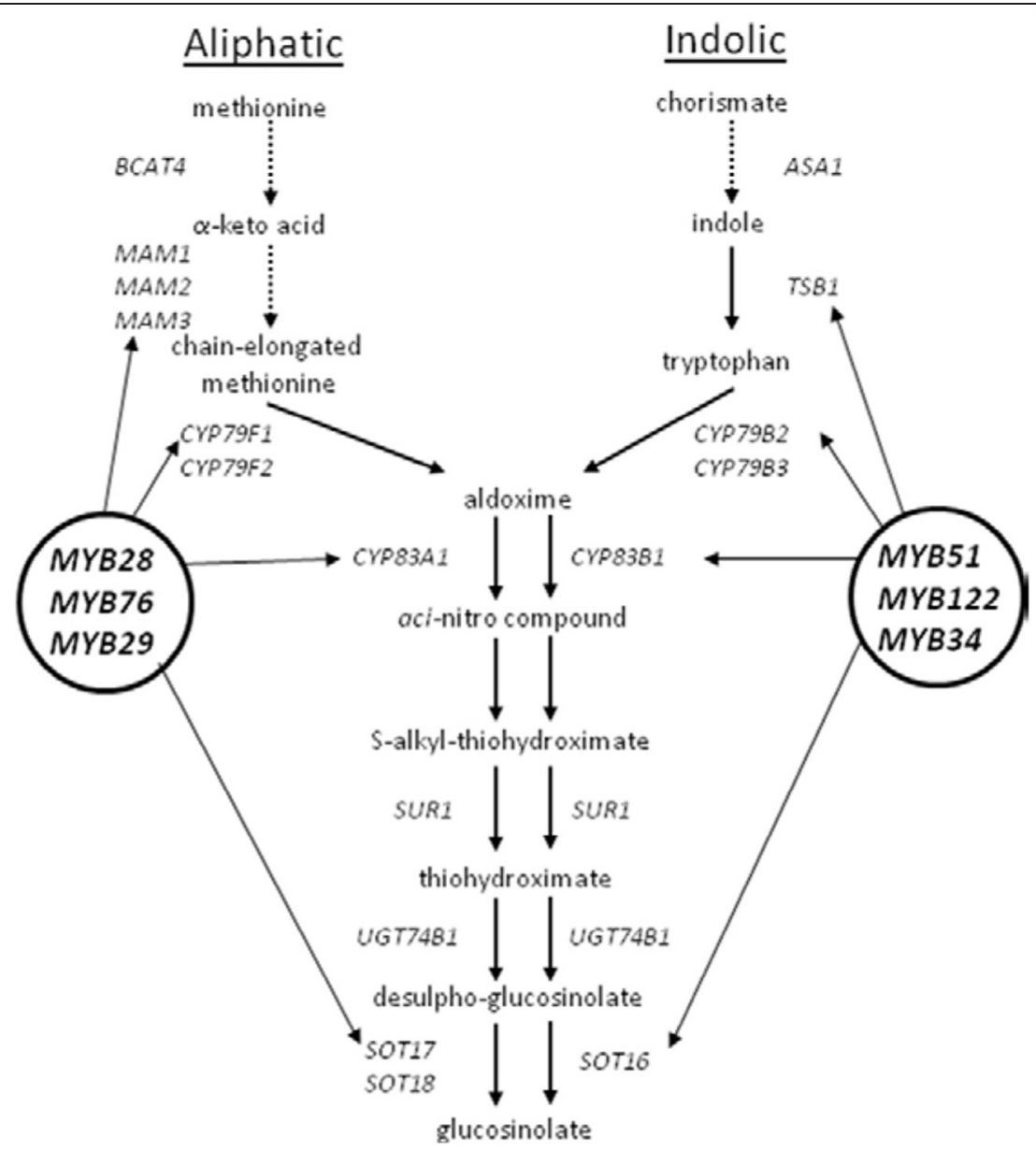

FIGURE A2 | Pathways for the biosynthesis of aliphatic (left) and indolic (right) glucosinolates.

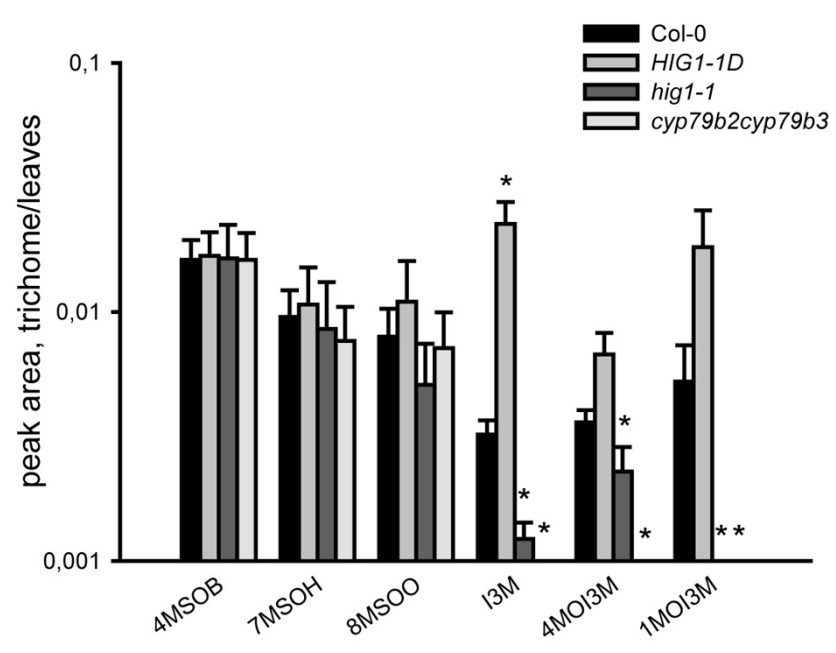

FIGURE A3 | Relative quantification of GS in methanolic extracts of detached trichomes vs. leaves of Col-0, MYB51-1D/HIG1-1D, myb51/hig1, cyp79b2cyp79b3 using UPLC/ESI-QTOF-MS. GS levels in trichomes are shown in relation to GS levels in leaves. Trichomes were collected as described in "Materials and Methods." Three biological and two technical replicates were used for the analysis. Error bars show SE of the mean. Peak areas are normalized to dry weights of trichomes and leaves. Significantly different values from the wild type at $P<0.05$ (Student's $t$-test) are marked by asterisk. 
Table A1 | Primer sequences for the Real-time PCR analysis.

\begin{tabular}{|c|c|c|c|}
\hline MYB28_Fw & At5g61420 & TCCCTGACAAATACTCTTGCTGAAT & MYB28 \\
\hline MYB28_Rv & & CATTGTGGTTATCTCCTCCGAATT & \\
\hline MYB29_Fw & At5g07690 & GAAATATGATGCTTCCTTGAGCTCC & MYB29 \\
\hline MYB29_RV & & ACGGTGTAGAGCTGATCAAGGTTC & \\
\hline MYB76_Fw & At5g07700 & ACGTTTTGGACGATCGAGCTCTAC & MYB76 \\
\hline MYB76_RV & & TGATTGAGAGAACGAGTCTGGGAGT & \\
\hline MYB34/ATR1_Fw & AT5G60890 & CACGACTGTCGATAATTTTGGGTT & MYB34 \\
\hline MYB51_Rv & & ACGAAATTATCGCAGTACATTAGAGGA & \\
\hline MYB122_Fw & AT1G74080 & АССТCTTCGAATCTCCССАTC & MYB122 \\
\hline MYB122_Rv & & AACTTCATTGATCGGCGTCAC & \\
\hline SAND_FW & AT2G28390 & AACTCTATGCAGCATTTGATCCACT & SAND \\
\hline SAND_Rv & & TGATTGCATATCTTTATCGCCATC & \\
\hline MAM1_Rv & & AGCCGTTAGACTTTAAACCGTTAGC & \\
\hline CYP79B3_Fw & At2g22330 & СТССТTСТTССTTGCAAATGGA & CYP79B3 \\
\hline CYP79B3_Rv & & GAGAATCATCAAGAAGCAAAGGG & \\
\hline CYP83B1_Fw & At4g31500 & GGCAACAAACCATGTCGTATCAAG & CYP83B1 \\
\hline CYP83B1_Rv & & CGTTGACACTCTTCTTCTCTAACCG & \\
\hline CYP83A1_Fw & At4g13770 & TTCAAGAGGTTGTCAATGAGACGC & CYP83A1 \\
\hline CYP83A1_Rv & & CTACAATATCCAAGATGACGGCTTT & \\
\hline GL2_Fw & AT1G79840 & ATGAAGCTCGTCGGCATGAGTGGG & GLABRA2 \\
\hline GL2_RV & & TGGATTGCCACTGAGTTGCCTCTG & \\
\hline LHCBI_Fw & At1g29910 & TTC СCT GGA GAC TAC GGA TG & LHCBI \\
\hline LHCB1_Rv & & CCC ACC TGC TTG GAT AAC T & \\
\hline
\end{tabular}

Table A2 | Accurate mass measurements of sodiated molecular ions of $\omega$-methylsulphinylalkyl-nitriles using UPLC/ESI(+)-QTOFMS.<smiles>CS(=O)C1CCC1C#N</smiles>

\begin{tabular}{|c|c|c|c|c|c|}
\hline$n$ & Elem. comp. & Ret. time [s] & \multicolumn{3}{|c|}{ Sodiated molecular ion $[\mathrm{M}+\mathrm{Na}]^{+}$} \\
\hline 4 & $\mathrm{C}_{6} \mathrm{H}_{11} \mathrm{NOS}$ & 68 & 168.04536 & 168.0448 & +3.5 \\
\hline 7 & $\mathrm{C}_{9} \mathrm{H}_{17} \mathrm{NOS}$ & 275 & 210.09231 & 210.0915 & +3.7 \\
\hline 8 & $\mathrm{C}_{10} \mathrm{H}_{19} \mathrm{NOS}$ & 334 & 224.10796 & 224.1084 & -1.8 \\
\hline
\end{tabular}


Table A3 | Collision-induced dissociation mass spectra $[\mathrm{m} / \mathrm{z}$ (relative intensity)] obtained from protonated molecular ions of $\omega$-methylsulphinylalkyInitriles using UPLC/ESI(+)-OTOFMS.

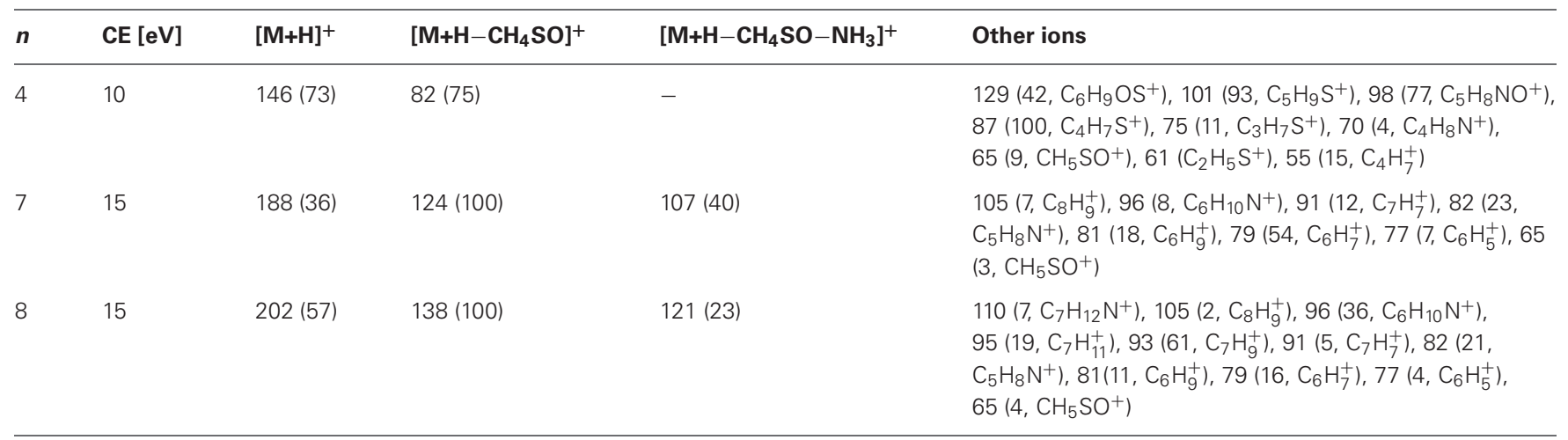

Elemental compositions of observed fragment ions are supported by accurate mass measurements ( $\pm 10 \mathrm{ppm})$. CE, collision energy. 